\title{
Material gap membrane distillation: A new design for water vapor flux enhancement
}

\author{
Lijo Francis, Noreddine Ghaffour, Ahmad A. Al-Saadi, Gary L. Amy \\ Water Desalination and Reuse Center, King Abdullah University of Science and Technology (KAUST), 23955-6900 \\ Thuwal, Saudi Arabia, Tel. +96628082180,Email: noreddine.ghaffour@kaust.edu.sa
}

\begin{abstract}
A new module design for membrane distillation, namely material gap membrane distillation (MGMD), for seawater desalination has been proposed and successfully tested. It has been observed that employing appropriate materials between the membrane and the condensation plate in an air gap membrane distillation (AGMD) module enhanced the water vapor flux significantly. An increase in the water vapor flux of about $200 \%$ to $800 \%$ was observed by filling the gap with sand and DI water at various feed water temperatures. However, insulating materials such as polypropylene and polyurethane have no effect on the water vapor flux. The influence of material thickness and characteristics has also been investigated in this study. An increase in the water gap width from $9 \mathrm{~mm}$ to $13 \mathrm{~mm}$ increases the water vapor flux. An investigation on an AGMD and MGMD performance comparison, carried out using two different commercial membranes provided by different manufacturers, is also reported in this paper.
\end{abstract}

Keywords: Desalination; Material gap membrane distillation (MGMD); Heat and mass transfer; Natural convection.

\section{Introduction}

Membrane Distillation (MD) is a thermally driven membrane-based separation process, which is considered as one of the emerging desalination technologies [1]. Rather than a pressure, concentration or an electrical potential gradient, the driving force for the MD process is the partial vapor pressure difference between the two sides of a hydrophobic microporous membrane. MD yields produced water with high quality, $99.99 \%$ salt rejection for Red Sea water 
desalination application [2]. The MD process operates at atmospheric pressure and at low temperatures $\left(30-80^{\circ} \mathrm{C}\right)$ [3], making it suitable for use of low grade energy sources such as waste heat, geothermal or solar energy [5-8]. Furthermore MD is a compact process and hence uses less space (foot print) and requires less maintenance [9].

The major configurations that have been employed in the MD process are direct contact membrane distillation (DCMD), air gap membrane distillation (AGMD), vacuum membrane distillation (VMD) and sweep gas membrane distillation (SGMD) [10,11]. In all configurations, the hot feed solution is in direct contact with the membrane. In DCMD, both hot (feed) and cold (clean water) streams are in direct contact with the membrane. In AGMD, a stagnant air gap is maintained between the membrane and a condensation surface on the permeate side. In VMD and SGMD, vacuum and a dry inert gas are passed through the permeate side, respectively, so that the vapor passing across the membrane from the feed side condenses outside the MD module. All of these configurations have been investigated in bench scale and found to be applicable to various matrices such as separation of non-volatiles like ions, macromolecules, cells, colloids [12-15], the removal of trace volatile organics [16-19], concentration of oil-water emulsions, acids and juice [20-22], biomedical applications [23,24], desalination and waste water treatment [1-3, 25-29]. Most of the bench scale work has been done with DCMD module, but recent pilot scale studies focused on AGMD and VMD configurations [30-33]. It is important to mention that in DCMD, the product is mixed with the coolant, whereas in AGMD there is the presence of a stagnant air layer between the membrane and the condensation surface so that any water type quality (e.g. seawater) can be used as a coolant. The air gap considerably reduces the heat loss by conduction as well as the temperature polarization effect. In recent work, Cipollina et al. [8] demonstrated a special design using permeate in the gap of an AGMD module (permeate gap MD). They found an increase in the water vapor flux from $10.4 \mathrm{~kg} / \mathrm{m}^{2} . \mathrm{h}$ to 12 $\mathrm{kg} / \mathrm{m}^{2} . \mathrm{h}$, at an air gap of $3 \mathrm{~mm}$ and $\Delta \mathrm{T}$ of $60^{\circ} \mathrm{C}$, for AGMD and permeate gap MD configurations, respectively.

In this paper, a new module design has been proposed for the MD process, called material gap membrane distillation (MGMD), and successfully tested using Red Sea water as feed solution. The MGMD consists of filling the gap between the membrane and the condensation plate with different materials having different characteristics such as poly urethane (sponge), poly propylene mesh, sand, and de-ionized water. The effect of these materials on the water 
vapor flux during the MGMD process has been studied and compared with AGMD flux under the same operating conditions. The effect of material thickness and feed flow rate on water vapor flux have been investigated and reported. AGMD/MGMD water vapor flux performance comparison has also been carried out using commercially available membranes provided by different manufacturers at different feed inlet temperatures.

\section{Theory}

AGMD is characterised by the presence of a stagnant air layer between the membrane and the condensation surface. The water vapor molecules in this configuration pass through the membrane pores and across the stagnant air layer before they get condensed on the cold plate inside the module. The air gap considerably reduces the heat loss. However, it introduces a new mass transfer resistance that decrease the permeate flux. A detailed investigation on the theoretical modeling and experimental validation of the AGMD process has been presented in our previous work [34]. By using the model developed in the latter paper, the modeling of water vapor mass transfer through an AGMD membrane and through the air gap as well as their combination has been developed separately, and is presented in Figure 1. The modeling is conducted at different feed inlet temperatures and different air gap thicknesses assuming no temperature polarization is taking place near the membrane and the coolant plate surfaces.

Figure 1: Modeling of the combination and individual mass fluxes through an AGMD membrane and through the air gap layer at different feed inlet temperatures and different air gap widths. The modeling assumes the following membrane characteristics: pore size $=0.2 \mu \mathrm{m}$, tortuosity $=2$, porosity $=0.7$ and thickness $=200 \mu \mathrm{m}$ ).

From Figure 1 it is clearly shown that the total AGMD flux can be approximated by the molecular diffusion equation for air gap thicknesses greater than $5 \mathrm{~mm}$. On the contrary, the total AGMD flux is best approximated by Knudsen diffusion as the molecular diffusion resistance becomes less than $1 \mathrm{~mm}$ (this value varies according to the structure properties of the membrane). Moreover, it could be conclude that the removal of non-condensable gases always improves the water flux until it becomes limited by the membrane structure resistance. 
Some of the possible methods that can be applied to reduce the molecular diffusion resistance are:

1. Increasing the feed temperature up to $100^{\circ} \mathrm{C}$ : As shown in Figure 1, as the feed inlet temperature approaches the saturation temperature at $1 \mathrm{~atm}$, the total AGMD flux gets closer to the membrane one regardless of the air gap width.

2. Total removal of the non-condensable gases from the module: Gostoli et al. [35] tested a flat sheet air gap module under different air gap pressures lower than the atmospheric pressure and found that the flux increases as the air gap pressure decreases. Similarly, Guijt et al. [36] removed the non-condensable gases from their air gap hollow fiber module and observed that the flux increased by three-folds.

3. Reducing the air gap width to less $1 \mathrm{~mm}$ : Jonsson's theoretical work [37] and Kimura's experimental studies [38] showed that the flux decreases as the air gap thickness increases. The first two methods are considered as two faces of one coin. The removal of the noncondensable gases can be achieved either by modifying the feed temperature until it reaches the module pressure or by reducing the module pressure until it reaches the saturation pressure of the feed temperature. However, elevating the feed temperature up to $100^{\circ} \mathrm{C}$ is contradicting the main goal of developing this technology (energy consumption). On the other hand, the reduction of the module pressure until it reaches the saturation pressure of the feed temperature presents technical difficulty in maintaining the sub-atmospheric pressures within the module.

The third method is considered to be the simplest one and can be done in two different ways. First, through the conventional way of fixing the cooling plate closer to the membrane surface, which is technically very challenging for air gap widths of less than $3 \mathrm{~mm}$; Second, through displacement of the non-condensable gases with other filling materials, as it is proposed in this paper.

MGMD configuration is comparable to the DCMD configuration in terms of heat transfer mainly due to the high heat loss through conduction. Moreover, the temperature polarization effect is expected to increase at the permeate side for the following reasons:

1. There is no forced-convective heat transfer at the permeate side as it is the case in the DCMD configuration. 
2. There is no heat transfer through vapor mass transfer as it is the case in the AGMD configuration. Hence, all the heat should be transferred by conduction through the filling material.

However, this new configuration still maintains the AGMD configuration advantages, mainly separating the permeate from the cooling medium.

In all thermal separation process heat and mass transfers are combined. Improving one of these transfer mechanisms cannot be done without considering the other. Thus, enhancing AGMD flux through the MGMD configuration cannot be achieved without studying the heat transfer mechanism inside the MGMD module.

The total heat flux across the MGMD membrane can be treated as the heat transfer across an AGMD membrane according to the following equation:

$Q=\frac{k}{b}\left(T_{h m}-T_{m f m}\right)+J_{v} h_{g}$

where $h_{g}$ is the enthalpy of the water vapor, $b$ is the membrane thickness, $T_{h m}$ is the hot feed temperature near the membrane, $T_{m f m}$ is the temperature at the interface of the filling material and the membrane. The average thermal conductivity $(k)$ of the membrane is calculated by:

$k=\varepsilon k_{\text {air }}+(1-\varepsilon) k_{m}$

where $k_{\text {air }}$ is the thermal conductivity of the air inside the membrane pores, and $k_{m}$ is the thermal conductivity of the membrane material. In Eq. (1), the first term is the sensible heat transfer through conduction and the second term is the latent heat transfer of water vapor.

For solid filling material, the heat transfer is only made through conduction according to the following equation:

$$
Q=\frac{k_{f m w}}{\delta_{f m}}\left(T_{m f m}-T_{f m w}\right)
$$

where $T_{f m w}$ is the temperature at the interface of the filling material and the wall of the cooling plate, $\delta_{f m}$ is the thickness of the filling material, and $k_{f m w}$ is the thermal conductivity of the water saturated filling material which can be calculated from the following equation:

$$
k_{f m w}=k_{f m d}\left(\frac{k_{l}}{k_{\text {air }}}\right)
$$

where $k_{f m d}$ is the thermal conductivity of the dry filling material, and $\mathrm{k}_{l}$ is the thermal conductivity of the liquid water. 
For liquid filling material, the heat transfer by conduction might be enhanced by natural convection caused by the temperature difference at the boundary layer of the filling liquid. The extent of natural convection heat transfer enhancement is correlated to a dimensionless number referred to as the Rayleigh number (Ra) [40]:

$R a=\frac{g \beta\left(T_{m f m}-T_{f m w}\right) \delta_{f m}^{3}}{v^{2}} P r$

where $g$ is acceleration due to gravity, $\beta$ is the thermal expansion coefficient of the fluid, is the kinematic viscosity of the fluid, and $\operatorname{Pr}$ is the Prantle's number. The fluid property in this equation is evaluated at the average temperature across the fluid:

$\frac{\left(T_{m f m}-T_{f m w}\right)}{2}$

For $\mathrm{Ra}>1,708$, the natural convection is initiated because at this value the buoyant force overcomes the fluid resistance. For $\mathrm{Ra}>3 \times 10^{3}$, turbulent regime is expected to develop inside the gap. The contribution of the natural convection to heat transfer can be calculated as [38]:

$Q=\frac{k_{f m} N u}{\delta_{f m}}\left(T_{m f m}-T_{f m w}\right)$

where $\mathrm{Nu}$ is the Nusselt's number. For $\mathrm{Ra}<1,708$ where natural convection is negligible, $\mathrm{Nu}=1$. For larger $\mathrm{Ra}, \mathrm{Nu}$ can be calculated using different correlation equations reported for vertical enclosures. One of these equations which are applicable to our experimental setup is the following [40]:

$N u=0.42 \operatorname{Ra}^{0.25} \operatorname{Pr}^{0.012}\left(\frac{H}{\delta_{f m}}\right)^{-0.3}$

$10<\frac{H}{\delta_{f m}}<40$

$1<\operatorname{Pr}<2 \times 10^{4}$

$10^{4}<R a<10^{7}$

where $\mathrm{H}$ is the height of the module. At relatively high Reynolds's number inside the feed and coolant flow channels, the convective heat transfer inside the coolant and feed channels is 
expected to be high. The heat transfer through the membrane is also high due to the high water vapor enthalpy passing through the membrane pores. The thermal conductivity of metallic plates is high; therefore, the heat transfer through thin sheet is expected to be high. Therefore, one may expect that the controlling heat transfer resistance in this configuration is that of the filling material, especially when the material used has poor thermal conductivity. The schematic diagram of the MGMD configuration is presented in Figure 2 (b).

\section{Experimental}

\subsection{Membranes}

Commercially available hydrophobic microporous poly tetrafluoroethylene (PTFE) membranes (M1 and M2) with a nominal pore size of $0.2 \mu \mathrm{m}$ provided by different manufacturers were tested in AGMD and MGMD configurations. Membranes were characterized for their thickness, pore size and contact angle. Their characteristics are given in Table 1. A detailed characterization of these membranes was reported in previous work [2].

Table 1: Membranes characteristics.

A digital micrometer, DML 3032 from Digital Micrometers LTD, UK, was used to determine the thickness of the membranes. Pore size of the membranes was measured using a porometer (IB-FT Gm bH Porolux 1000, Germany) by the wet-up/dry-up method with an Automated Capillary Flow Porometer System software. The water contact angle of the membranes was measured using a goniometer (Attension, KSV instruments T 301, Finland).

\subsection{Feed water and materials}

Red Sea water collected from the King Abdullah University of Science and Technology seawater reverse osmosis (KAUST-SWRO) plant [41] and filtered through a $10 \mu \mathrm{m}$ filter, to remove large suspended solids, was used as feed solution, whereas tap water was used as coolant. Feed and coolant temperatures were controlled using a heater and chiller, respectively. A $10 \mathrm{~cm} \times 5 \mathrm{~cm}$ membrane specimen was employed in the MD module for AGMD and MGMD processes testing. The materials used to fill the space between the membrane and the 
condensation plate were poly urethane (sponge), poly propylene mesh, sand, and de-ionized (DI) water. A poly propylene zigzag spacer was used on the membrane feed side in all experiments. This spacer serves not only as a membrane support but also as a turbulence promoter.

The MD bench scale module designed and fabricated in our workshop was mounted vertically to assure that all the gap volume is filled with the material used in MGMD process. Sand samples were collected from different regions of the Red Sea coast and sieved to remove coarse particles. Porosity of the sand was determined by calculating the ratio of water to sand performed in a jar measurement.

\subsection{Experimental unit and measurements}

The flow channel dimensions of both feed and coolant sides were $(100 \mathrm{~mm} \times 50 \mathrm{~mm} \times 2$ $\mathrm{mm}$ ) each. Temperature, pressure, conductivity and flow rates of the feed solution and coolant were monitored using appropriate sensors and connected to a data acquisition system equipped with Lab View software. A conductivity meter (Oakton Eutech Instruments, Malaysia) was used to determine the salt concentrations of both permeate and feed solutions. Conductivity of the feed solution was kept constant throughout the experiment by slowly adding distilled water into the system to compensate the evaporated water (MD product). Permeate was collected from the bottom side of the module during the AGMD process whereas it was collected from the top side of the module during the MGMD process. A AGMD and MGMD performance comparison using M1 and M2 membranes at different air/material gap widths and at different feed solution temperatures was carried out and reported. The schematic diagram of the bench scale MGMD set up and MGMD configuration are shown in Figure 2 (a) and (b), respectively.

Figure 2: A schematic diagram of (a) the MGMD bench scale setup, (b) MGMD configuration.

\section{Results and discussion}

Figures 3 and 4 show the water vapor flux versus feed inlet temperature obtained by AGMD, sand gap MD, DI water gap MD (WGMD), sponge (polyurethane) gap MD (PUGMD), and polypropylene mesh gap MD (PPGMD) configurations at $9 \mathrm{~mm}$ and $13 \mathrm{~mm}$ gap widths. Coolant 
temperature and feed/coolant flow rates were kept constant at $20{ }^{\circ} \mathrm{C}$ and $1.5 \mathrm{~L} / \mathrm{min}(\mathrm{LPM})$ (equivalent to a cross-flow velocity of $0.25 \mathrm{~m} / \mathrm{s}$ ), respectively. MD membranes were a total barrier for ions achieving more than $99.99 \%$ of salt removal (conductivity reduced from 61,400 $\mu \mathrm{s} / \mathrm{cm}$ to less than $15 \mu \mathrm{s} / \mathrm{cm}$ in all experiments).

Figure 3: Water vapor flux profile versus feed inlet temperature during the AGMD and MGMD processes at $9 \mathrm{~mm}$ gap width, using M1 membrane.

Figure 4: Water vapor flux profile versus feed inlet temperature during the AGMD and MGMD processes at $13 \mathrm{~mm}$ gap width, using M1 membrane.

Variation in the water vapor flux was observed by employing different materials between the microporous hydrophobic membrane and the condensation plate. During the AGMD process the heat and mass transfer resistance come mostly from the air gap. Moreover the surface area of condensation is limited to the area of the condensation plate. By employing different materials in the MGMD process the air gap is reduced and the surface area of condensation is significantly increased. While employing insulating materials such as sponge and poly propylene in the air gap, the heat transfer hindrance during the MGMD process dominates over the reduction in the air gap and the water vapor flux was found to be lesser than that in the AGMD process. The use of DI water and sand in the air gap enhances the heat transfer along with a reduction in the air gap width and an increase in the condensation surface area providing a synergic effect, which helps in increasing the water vapor flux.

Figure 5 shows the water vapor flux profile observed during the AGMD, WGMD and sand gap MD configurations at $9 \mathrm{~mm}$ and $13 \mathrm{~mm}$ gap widths using M1 membrane.

Figure 5: Water vapor flux profile versus feed inlet temperature during AGMD, WGMD and sand GMD processes at $9 \mathrm{~mm}$ and $13 \mathrm{~mm}$ gap widths, using M1 membrane.

During AGMD and sand gap MD a flux increase of about $25 \%$ was observed at a feed inlet temperature of $80^{\circ} \mathrm{C}$ by reducing the gap width from $13 \mathrm{~mm}$ to $9 \mathrm{~mm}$, but the effect is negligible at lower feed inlet temperatures. The highest water vapor flux for all experiments was obtained 
in WGMD. Water fills all the gap volume making this process similar to the DCMD configuration but the coolant here is not mixed with the permeate as it is flowing on the other side of the condensation plate, which enables using any water quality as coolant. However, in WGMD the gap width seems to have insignificant effect on the flux at any feed inlet temperature.

Figure 6 shows the increase in the percentage of flux enhancement for WGMD and sand gap MD with different air gap widths and for different feed inlet temperatures, compared to AGMD performance, using M1 membrane.

Figure 6: Percentage of water vapor flux enhancement during the WGMD and sand gap MD processes compared to the AGMD process, using M1 membrane.

The percentage flux enhancement was found to be reduced while increasing the feed inlet temperature from $40{ }^{\circ} \mathrm{C}$ to $80^{\circ} \mathrm{C}$. For the WGMD configuration at $13 \mathrm{~mm}$ gap width, an $820 \%$ increase in water vapor flux, when compared to the AGMD process, was observed at a feed inlet temperature of $40{ }^{\circ} \mathrm{C}$, whereas it reaches about $400 \%$ at $80{ }^{\circ} \mathrm{C}$. The same trend was observed in the sand gap MD process. The heat developed in the materials at higher temperatures decreases the mass transfer during the MGMD process, a possible reason for the reduction in the percentage flux enhancement.

Figure 6 also reveals that the increase in the water gap helps to improve the flux compared to the AGMD process. The increase in the water gap width from $9 \mathrm{~mm}$ to $13 \mathrm{~mm}$ increases the percentage flux from $572 \%$ to $820 \%$ at $40{ }^{\circ} \mathrm{C}$, and from $340 \%$ to $429 \%$ at $80{ }^{\circ} \mathrm{C}$. The latent heat of condensation of water vapor has more area to dissipate at higher gap widths, which results in the increased mass transfer leading to flux enhancement. When using sand as material between the membrane and the condensation plate, the effective air gap has been reduced depending upon the characteristics of the sand. The air trapped between the voids will be saturated by the condensate and both the properties of the permeate and sand together contribute to the heat and mass transfer during the MGMD process. The heat transfer capacity of the water dominates the sand and results in greater increase of water vapor flux in WGMD than in sand gap MD. Moreover, as explained in Eqs. 5-8, at higher gap widths, the heat transfer is again enhanced by natural convection since the Ra number is calculated to be greater than 1,708 which results in the 
increased mass transfer. In Cipollina et al. PGMD study [8], the permeate gap used is probably not large enough to dominate the natural convection in the permeate channel.

Figure 7 shows the AGMD, sand gap MD and WGMD performance comparison between M1 and M2 membranes at $13 \mathrm{~mm}$ gap width and at different feed inlet temperatures.

Figure 7: Water vapor flux profile comparison between M1 and M2 membranes during the AGMD, sand gap MD and WGMD processes at $13 \mathrm{~mm}$ gap width.

During the WGMD process, the M2 membrane yields a water vapor flux of $11.2 \mathrm{~kg} / \mathrm{m}^{2} . \mathrm{h}$ at feed and coolant inlet temperatures of $80^{\circ} \mathrm{C}$ and $20^{\circ} \mathrm{C}$, respectively; whereas the M1 membrane yields a water vapor flux of $20.45 \mathrm{~kg} / \mathrm{m}^{2}$.h under the same operating conditions. The active layer of both membranes is made of the same material and has a comparable mean flow pore size and first bubble point, yet the M1 membrane shows approximately a two-fold increase in the water vapor flux at any feed inlet temperature; this suggests that other membrane properties such as tortuosity, porosity, thickness and support material could play an important role in the mass and heat transfer during the MD process. The high flux obtained by the M1 membrane is attributed to its lower thickness and higher contact angle compared to the M2 membrane (Table 1). The thickness of the membrane used in this study $(100 \mu \mathrm{m})$ is much thinner than that used in the PGMD investigation $(240 \mu \mathrm{m})$ [8], which could also explain the significant variation in the permeate flux.

Figure 8 (a) and (b) show the effect of flow rate on water vapor flux during the AGMD process at different feed inlet temperatures for M1 and M2 membranes, respectively. Both membranes showed similar trends with a slight increase in the flux by increasing the feed flow rate from $0.5 \mathrm{LPM}$ to $1.5 \mathrm{LPM}$ (equivalent to cross-flow velocities of $0.08 \mathrm{~m} / \mathrm{s}$ and $0.25 \mathrm{~m} / \mathrm{s}$, respectively). The increase of feed flow rate leads to an increase of cross-flow velocity (shear stress) in the vicinity of the membrane surface which reduces the temperature polarization effect; hence increases the flux. No significant change in the temperature polarization at higher flow rates that has been employed to investigate the process could also be another reason for the insignificant increase in flux. Moreover, the increase is not significant due to the decrease of the residence time at higher cross-flow velocities [34]. 
Figure 8: Effect of flow rate on water vapor flux during the AGMD process at different feed inlet temperatures for (a) M1 and (b) M2 membrane.

The effect of feed flow rate on water vapor flux during sand gap MD, WGMD and AGMD, using M1 membrane is shown in Figure 9. Coolant flow rate and temperature were kept constant at $1.5 \mathrm{LPM}(0.25 \mathrm{~m} / \mathrm{s})$ and $20{ }^{\circ} \mathrm{C}$, respectively, and the gap width was fixed at $13 \mathrm{~mm}$.

Figure 9: Effect of feed flow rate on water vapor flux during sand gap MD, WGMD, and AGMD at feed inlet temperatures of $80^{\circ} \mathrm{C}, 60^{\circ} \mathrm{C}$ and at $80^{\circ} \mathrm{C}$, respectively, using $\mathrm{M} 1$ membrane.

By increasing the feed flow rate from 0.5 LPM to 1.5 LPM, it was found that an increase in the flux by approximately $15 \%$ was observed (from $7.3 \mathrm{~kg} / \mathrm{m}^{2} \cdot \mathrm{h}$ to $8.5 \mathrm{~kg} / \mathrm{m}^{2} \cdot \mathrm{h}$ and from 8.2 $\mathrm{kg} / \mathrm{m}^{2} . \mathrm{h}$ to $9.5 \mathrm{~kg} / \mathrm{m}^{2} . \mathrm{h}$ at feed inlet temperatures of $80^{\circ} \mathrm{C}$ and $60^{\circ} \mathrm{C}$, respectively) during the sand gap MD process. Temperature polarization is one of the possible phenomena responsible for the water vapor flux decline during the MD process. An increase in the feed flow rate decreases the thickness of the stagnant fluid film near the membrane surface and decreases the temperature polarization effect. Chenga et al., [41] found an increase in flux of about 20\% while increasing the feed flow rate from 4 LPM to 8 LPM. In order to increase the residence time of the feed solution and reduce the energy requirement, a maximum flow rate of 1.5 LPM was used in our study.

The majority of experimental data reported in the literature were obtained with a relatively high flow rates and large $\Delta \mathrm{T}$. These optimistic conditions are not feasible while scaling-up the MD system [2]. Thermal efficiency of the MD process is very low at large $\Delta \mathrm{T}$, because a large heat input is required to maintain the same temperature difference due to low heat recovery. The water vapor flux at these conditions will be large and far from the flux expected while using large scale modules. To mimic the large scale conditions, we have conducted different sets of experiments at low $\Delta \mathrm{T}$ across the membrane with different increments, i.e. from high feed inlet temperature and high coolant inlet temperature (e.g. $\mathrm{Th}=70^{\circ} \mathrm{C}$ and $\mathrm{Tc}=60^{\circ} \mathrm{C}$ ) to low feed inlet temperature and low coolant temperature (e.g. 
$\mathrm{Th}=40{ }^{\circ} \mathrm{C}$ and $\mathrm{Tc}=30^{\circ} \mathrm{C}$ ), because, at these conditions, the heat recovery is maximized at the expense of lowering the permeate flux.

Figure 10: AGMD, sand gap MD and WGMD performances at different $\Delta \mathrm{T}$ and at feed/coolant flow rates of 1.5 LPM, using M1 membrane.

Figure 10 shows the AGMD, sand gap MD and WGMD performances using the M1 membrane at different $\Delta \mathrm{T}$ and at constant coolant/feed solution flow rates of 1.5 LPM and a gap width of $13 \mathrm{~mm}$. Although the experiments were conducted at constant $\Delta \mathrm{T}$, a decrease in the water vapor flux was observed with a decrease in the feed inlet temperature. At $50{ }^{\circ} \mathrm{C}$ and at $\Delta \mathrm{T}$ of $10^{\circ} \mathrm{C}$, a water vapor flux of $1 \mathrm{~kg} / \mathrm{m}^{2}$.h was observed during the WGMD process, and under the same operating conditions, AGMD and sand gap MD processes gave a water vapor flux of 0.4 and $0.67 \mathrm{~kg} / \mathrm{m}^{2}$.h, respectively. An increase of $100 \%$ and $200 \%$ in the water vapor flux was observed while operating the WGMD process by increasing $\Delta \mathrm{T}$ from $10^{\circ} \mathrm{C}$ to $15^{\circ} \mathrm{C}$ and to $20^{\circ} \mathrm{C}$, respectively. A significant increase in the water vapor flux was also observed during the WGMD process at constant $\Delta \mathrm{T}$ in comparison with AGMD and sand gap MD processes under the same operating conditions, as shown in Figure 10.

The zigzag spacers used at the feed side of the membrane can reduce the thickness of the stagnant thermal boundary layer near the membrane surface and improve the heat transfer coefficient by reducing the temperature polarization, eventually maximizing the flux [43].

The effect of sand porosity on water vapor flux under the same operating conditions was also investigated (Fig. 11). Sand samples with four different porosities ranging from $27 \%$ to $47 \%$, were tested, using M1 membrane. An increase of porosity results in an increase of water vapor flux.

Figure 11. Effect of sand porosity on water vapor flux, coolant/feed temperature $=20^{\circ} \mathrm{C} / 80$ ${ }^{\circ} \mathrm{C}$, coolant/feed flow rates $=1.5 \mathrm{LPM}$, gap width $=13 \mathrm{~mm}$.

A water vapor flux of $7.92 \mathrm{~kg} / \mathrm{m}^{2}$.h was obtained while using $27 \%$ porous sand whereas the flux was increased to $9.2 \mathrm{~kg} / \mathrm{m}^{2}$.h while using $47 \%$ porous sand in the gap between the 
membrane and the condensation plate. That means a $15 \%$ increase in the flux was observed by increasing the porosity by $20 \%$. An increase in porosity allows more water vapor to occupy the voids and a synergic effect of sand and water vapor in the air gap at steady state helps in increasing the rate of vapor condensation and mass transfer, which in turns increases the water vapor flux.

\section{Conclusions}

A new MD module design, called MGMD, has been proposed for seawater desalination and successfully tested. Sand, DI water, sponge (polyurethane) and polypropylene mesh were used as materials to fill the gap between the membrane and the condensation plate of an AGMD module. A maximum increase of $820 \%$ in the water vapor flux was observed during the WGMD process when compared to the AGMD under the same operating conditions. Natural convection plays an important role in the heat and mass transfer phenomena at higher gap widths during the WGMD process. A water vapor flux of 4.77 $\mathrm{kg} / \mathrm{m}^{2}$.h with $99.99 \%$ salt rejection was obtained during the AGMD process, whereas a $428 \%$ increase in the flux was observed $\left(20.45 \mathrm{~kg} / \mathrm{m}^{2}\right.$.h $)$ in the MGMD process by using water in the gap at a feed and coolant inlet temperatures of $80^{\circ} \mathrm{C}$ and $20^{\circ} \mathrm{C}$, respectively. An increase in the water gap width from $9 \mathrm{~mm}$ to $13 \mathrm{~mm}$ increases the water vapor flux. Also, a $15 \%$ increase in the water vapor flux was observed for a three-fold increase in the feed flow rate during the WGMD and sand gap MD processes. Water vapor flux was also found to be higher by increasing the porosity of the sand used in the gap. It is necessary to do the experiments at low $\Delta \mathrm{T}$ across the membrane to mimic large scale module conditions, because at these conditions the heat recovery is maximized at the expense of lowering the water vapor flux.

\section{References}

[1] L. Francis, H. Maab, A. AlSaadi, S. Nunes, N. Ghaffour, G.L. Amy, Fabrication of electrospun nanofibrous membranes for membrane distillation application, Desalination and Water Treatment 51 (2013) 1337-1343. 
[2] L. Francis, N. Ghaffour, A. Al-Saadi, F. Wali, S.P. Nunes, G. L. Amy, High performance flat sheet membranes for Red Sea water desalination using direct contact membrane distillation, submitted to Journal of Membrane Science.

[3] H. Maab, L. Francis, A. Al-Saadi, C. Aubry, N. Ghaffour, G. Amy, S.P. Nunes, Synthesis and fabrication of nanostructured hydrophobic polyazole membranes for low-energy water recovery, J. Membr. Sci. 423-424 (2012) 11-19.

[4] N. Ghaffour, T.M. Missimer, G.L. Amy, Technical review and evaluation of the economics of water desalination: Current and future challenges for better water supply sustainability, Desalination 309 (2013) 197-207.

[5] Z. Ding, Analysis of a solar-powered membrane distillation system, Desalination 172 (2005) $27-40$.

[6] S. Bouguecha, M. Dhahbi, Fluidised bed crystalliser and air gap membrane distillation as a solution to geothermal water desalination, Desalination 52 (2003) 237-244.

[7] S. Adham, A. Hussain, J.M. Matar, R. Dores, A. Janson, Application of Membrane Distillation for desalting brines from thermal desalination plants, Desalination 314 (2013) 101-108.

[8] A. Cipollina, M.G. Di Sparti, A. Tamburini, and G. Micale, Development of a Membrane Distillation module for solar energy seawater desalination, Chemical Engineering Research and Design, 90 (12) (2012) 2101-2121.

[9] Y.D. Kim, K. Thu, N. Ghaffour, K.C. Ng, Performance investigation of solar-assisted hollow fiber DCMD desalination system, J. Membr. Sci. 427 (2013) 345-364.

[10] J.-P. Mericq, S. Laborie, C. Cabassud, Evaluation of systems coupling vacuum membrane distillation and solar energy for seawater desalination, Chemical Engineering Journal 166 (2011) 596-606.

[11] R.W. Schofield, A.G. Fane, C.J.D. Fell, Heat and mass transfer in membrane distillation, J. Membr. Sci. 33 (1987) 299-313.

[12] K.W. Lawson, D.R. Lloyd, Membrane distillation. I. Module design and performance evaluation using vacuum membrane distillation, J. Membr. Sci. 120 (1996) 111-121.

[13] M. Khayet, J.I. Mengual, G. Zakrzewska-Trznadel, Direct contact membrane distillation for nuclear desalination. Part II. Experiments with radioactive solutions, Int. J. Nucl. Desalinat. (IJND) 56 (2006) 56-73. 
[14] E. Drioli, V. Calabr`o, Y.Wu, Microporous membranes in membrane distillation, Pure Appl. Chem. 58 (12) (1986) 1657-1662.

[15] M. Sudoh, K. Takuwa, H. Iizuka, K. Nagamatsuya, Effects of thermal and concentration boundary layers on vapor permeation in membrane distillation of aqueous lithium bromide solution, J. Membr. Sci. 131 (1997) 1-7.

[16] F.A. Banat, J. Simandl, Removal of benzene traces from contaminated water by vacuum membrane distillation, Chem. Eng. Sci. 51 (8) (1996) 1257-1265.

[17] G.C. Sarti, C. Gostoli, S. Bandini, Extraction of organic-compounds from aqueous streams by vacuum membrane distillation, J. Membr. Sci. 80 (1993) 21-33.

[18] F.A. Banat, J. Simandl, Membrane distillation for propane removal from aqueous streams, J. Chem. Technol. Biotechnol. 75 (2) (2000) 168-178, AGMD.

[19] N. Qureshi, M.M. Meagher, R.W. Hutkins, Recovery of 2,3-butanediol by vacuum membrane distillation, Sep. Sci. Technol. 29 (13) (1994) 1733-1748.

[20] M. Gryta, K. Karakulski, The application of membrane distillation for the concentration of oil-water emulsions, Desalination 121 (1999) 23-29.

[21] M. Tomaszewska, M. Gryta, A.W. Morawski, Study on the concentration of acids by membrane distillation, J. Membr. Sci. 102 (1995) 113-122.

[22] V. Calabr'o, B.L. Jiao, E. Drioli, Theoretical and experimental study on membrane distillation in the concentration of orange juice, Ind. Eng. Chem. Res. 33 (71) (1994) 18031808.

[23] K. Sakai, T.K. Ano, T. Murai, et al., Effect of temperature polarization on water vapor permeability for blood in membrane distillation, Chem. Eng. Jpn. 38 (1988) 833.

[24] A. Capuano, B. Menoli, V.E. Andreucci, A. Criscuoli, E. Drioli, Membrane distillation of human plasma ultrafiltrate and its theoretical applications to haemodialysis techniques, Int. J. Artif. Organs 23 (7) (2000) 415-422.

[25] H. Maab, A.A. Saadi, L. Francis, S. Livazovic, N. Ghafour, G.L. Amy, S.P. Nunes, Polyazole Hollow Fiber Membranes for Direct Contact Membrane Distillation, Ind. Eng. Chem. Res., (2013) DOI: 10.1021/ie400043q.

[26] E. Drioli, A. Criscuoli, E. Curcio, Integrated membrane operation for seawater desalination, Desalination 147 (2002) 77-81. 
[27] V. Calabr`o, E. Drioli, F. Matera, Membrane distillation in the textile wastewater treatment, Desalination 83 (1991) 209-224.

[28] R.B. Saffarini, E.K. Summers, H.A. Arafat, J.H. Lienhard V, Technical evaluation of standalone solar powered membrane distillation systems, Desalination 286 (2012) 332-341.

[29] Winter, D., Koschikowski, J., Wieghaus, M., Desalination using membrane distillation: Experimental studies on full scale spiral wound modules, J. Membr. Sci. 375 (2011) 104112.

[30] K. Zhao, W. Heinzl,, M. Wenzel, S. Büttner, F. Bollen, G. Lange, S. Heinzl, N. Sarda, Experimental study of the memsys vacuum-multi-effect-membrane-distillation (V-MEMD) module, in press, Desalination, http://dx.doi.org/10.1016/j.desal.2012.12.003.

[31] A. Kullab, Desalination using membrane distillation: Experimental and numerical study, Doctoral Thesis 2011, Royal Institute of Technology, SE-100 44 Stockholm.

[32] J.H. Hanemaaijer, J. van Medevoort, A.E. Jansen, C. Dotremont, E. van Sonsbeek, T. Yuan, L.D. Ryck, Memstill membrane distillation - a future desalination technology, Desalination 199 (2006) 175-176.

[33] Z. Kui, W. Heinzl, F. Bollen, G. Lange, G. Van Gendt, A. Fane, Demonstrating solar-driven membrane distillation using Memsys vacuum-multi-effect-membrane-distillation, World Congress/Perth Convention and Exhibition Centre (PCEC), Perth, Western Australia September 4-9, 2011 Ref: IDAWC/PER11-214.

[34] A. Al-Saadi, N. Ghaffour, J.D. Li, S. Gray, L. Francis, H. Maab, S. Nunes, G. Amy, Modeling of air-gap membrane distillation process: A theoretical and experimental study, in Press, J. Membr. Sci. doi.org/10.1016/j.memsci.2013.05.049.

[35] C. Gostoli, G.C. Sarti, S. Matulli, Low-Temperature Distillation through Hydrophobic Membranes, Separation Science and Technology 22 (1987) 855-872.

[36] C.M. Guijt, G.W. Meindersma, T. Reith, A.B. de Haan, Air gap membrane distillation: 2. Model validation and hollow fibre module performance analysis, Separation and Purification Technology 43 (2005) 245-255.

[37 ] A.S. Jonsson, R. Wimmerstedt, A.C. Harrysson, Membrane distillation - a theoritical study of evaporation through microporous membranes, Desalination 56(1985) 237-249.

[38 ] S. Kimura, S.I. Nakao, S.I. Shimatani, Transport phenomena in membrane distillation, J. Membr. Sci. 33 (1987) 285-298. 
[39] V.V. Ugrozov, I.B. Elkina, V.N. Nikulin, L.I. Kataeva, Theoretical and experimental research of liquid-gap membrane distillation process in membrane module, Desalination 157 ( 2003) 325-331.

[40] Cengel, Yunus A., Robert H. Turner, and John M. Cimbala, (2008). Fundamentals of Thermal Fluid Sciences, Boston: McGraw-Hill, pp. 924-929.

[41] K. Rahmawati, N. Ghaffour, C. Aubry, G.L. Amy, Boron removal efficiency from Red Sea water using different SWRO/BWRO membranes, J. Membr. Sci. 423-424 (2012) 522-529.

[42] L.-H. Chenga, Y.-H. Lin, J. Chen, Enhanced air gap membrane desalination by novel finned tubular membrane modules, J. Membr. Sci. 378 (2011) 398- 406.

[43] L.M. Camacho, L. Dumee, J. Zhang, J-D. Li, M. Duke, J. Gomez, S. Gray, Advances in Membrane Distillation for Water Desalination and Purification Applications, Water 5 (2013) 94-196 
Table 1: Membranes characteristics.

\begin{tabular}{ccccc}
\hline $\begin{array}{c}\text { Membrane } \\
\text { type }\end{array}$ & $\begin{array}{c}\text { Mean flow } \\
\text { pore size }(\mu \mathrm{m})\end{array}$ & $\begin{array}{c}\text { First bubble } \\
\text { point }(\mu \mathrm{m})\end{array}$ & $\begin{array}{c}\text { Thickness } \\
(\mu \mathrm{m})\end{array}$ & $\begin{array}{c}\text { Water contact } \\
\text { angle }\left({ }^{\circ}\right)\end{array}$ \\
\hline PTFE M1 & 0.24 & 0.38 & 100 & 160 \\
PTFE M2 & 0.26 & 0.42 & 170 & 140 \\
\hline
\end{tabular}

- A new module design for MD, namely Material Gap MD has been proposed and tested.

- A MGMD module was designed and fabricated in the laboratory.

- Sand, DI water, polyurethane and polypropylene mesh materials were used.

- MGMD performance was compared to the AGMD process under the same conditions.

- MD scale-up issues are also discussed in this paper. 


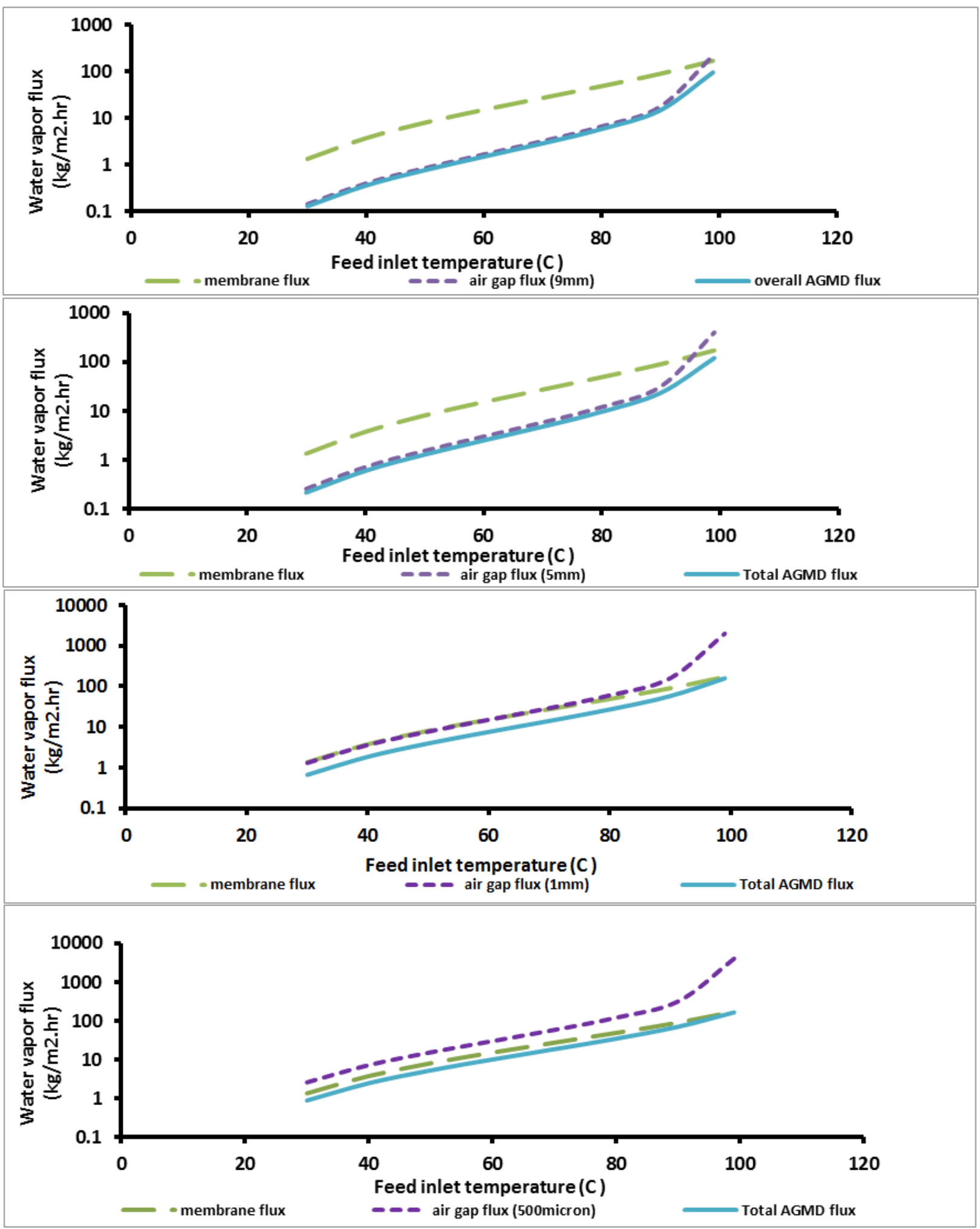

Figure 1 


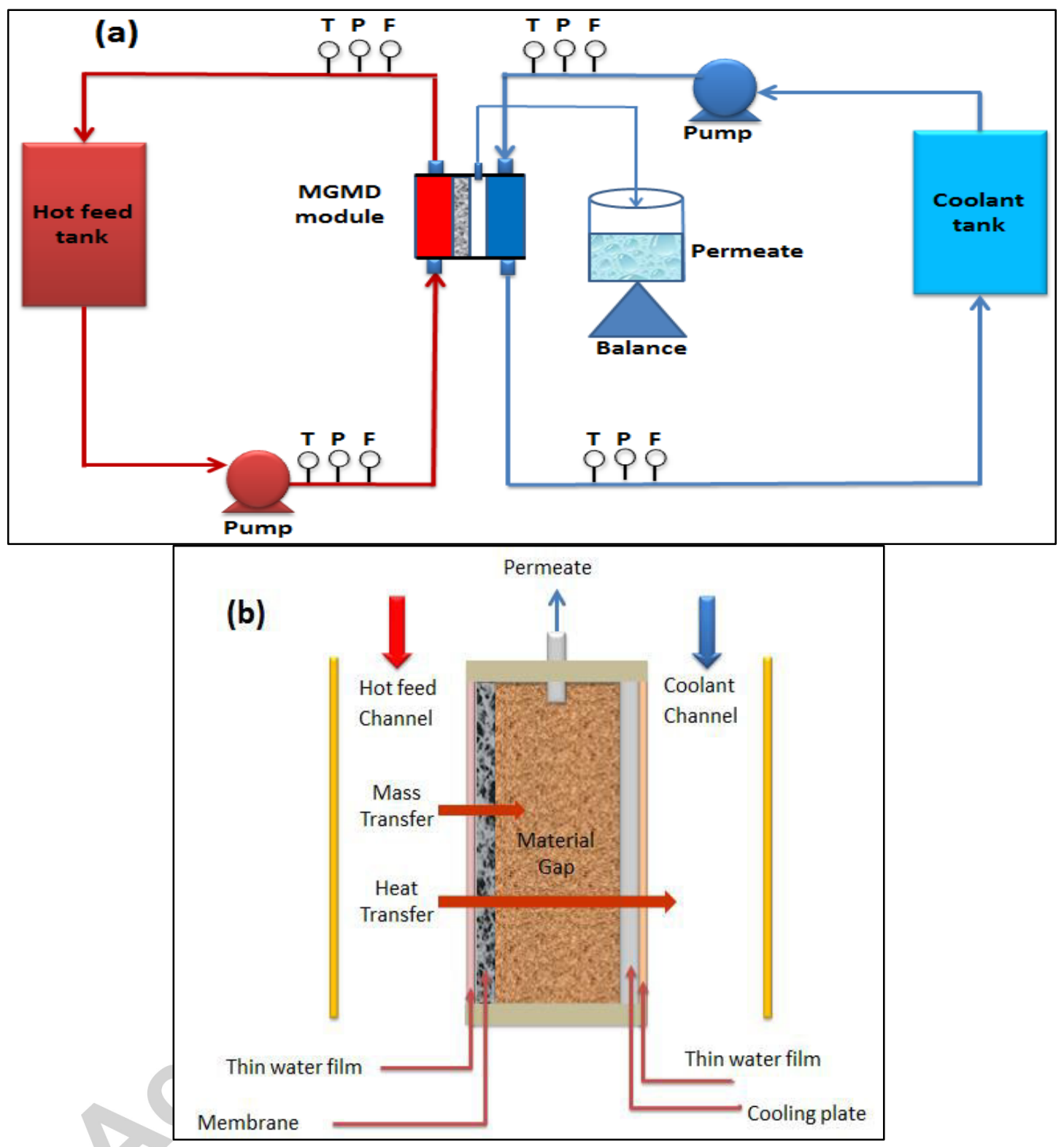

Figure 2 


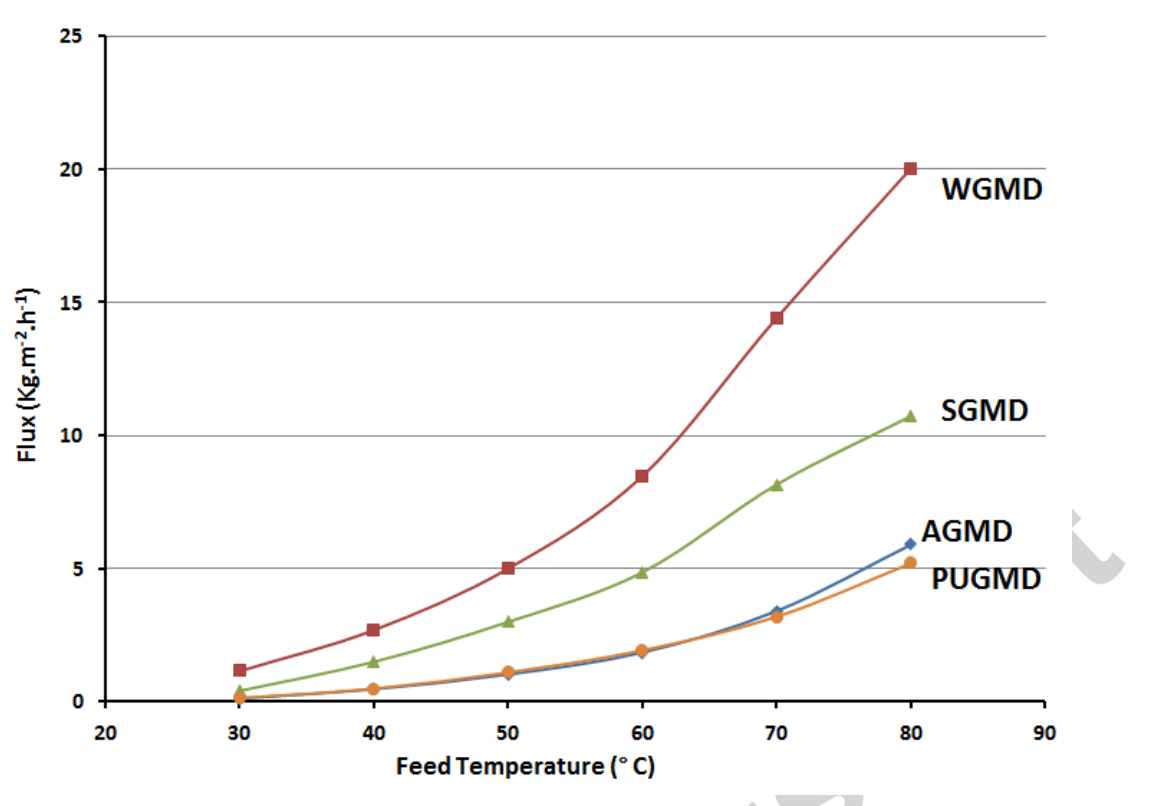

Figure 3
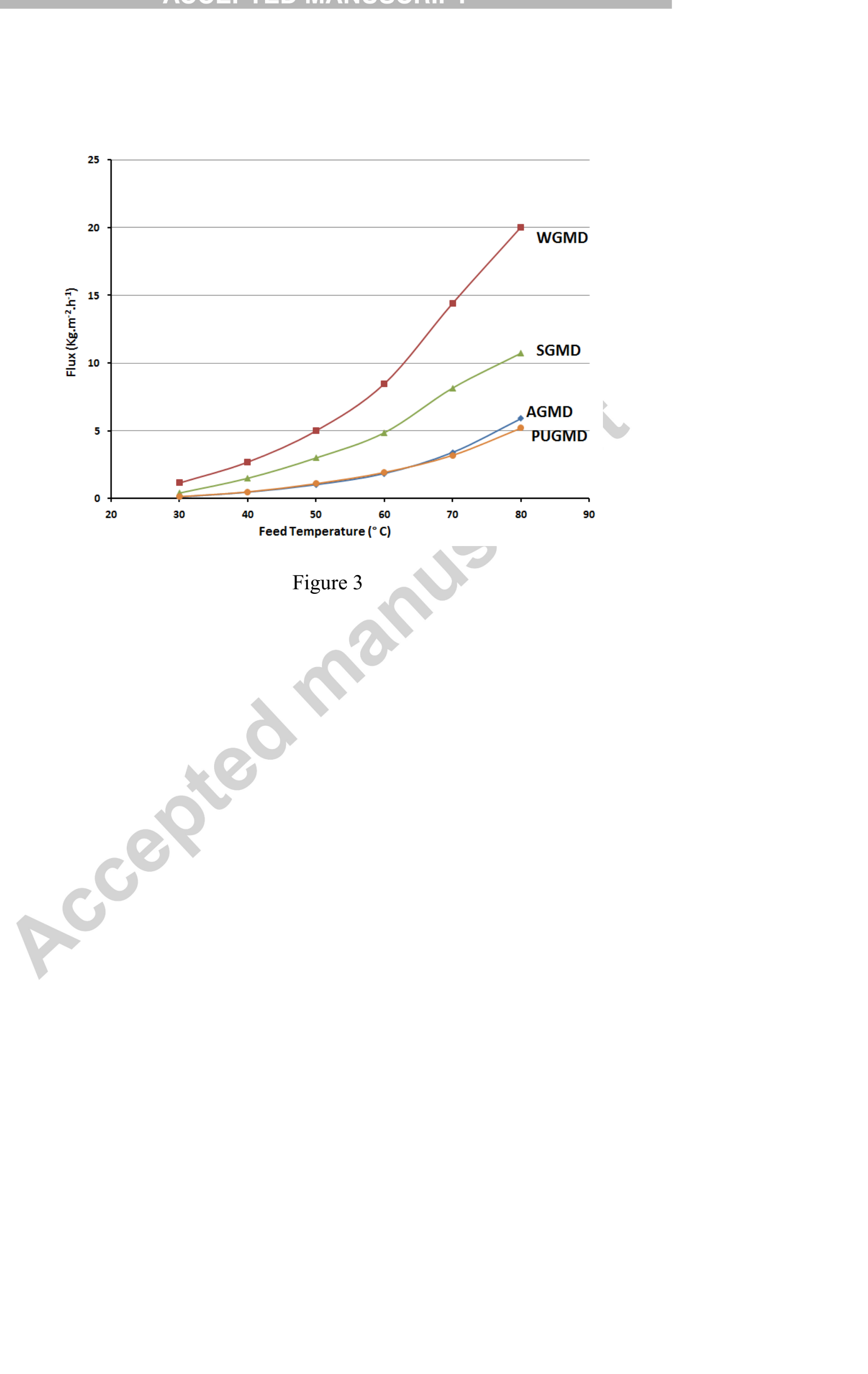

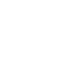

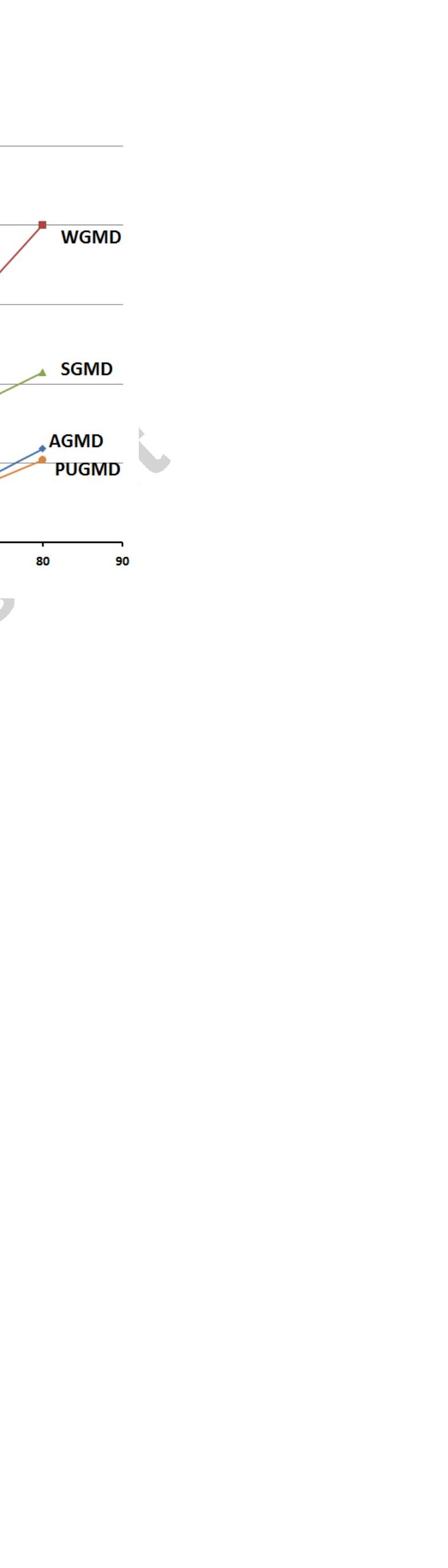
.
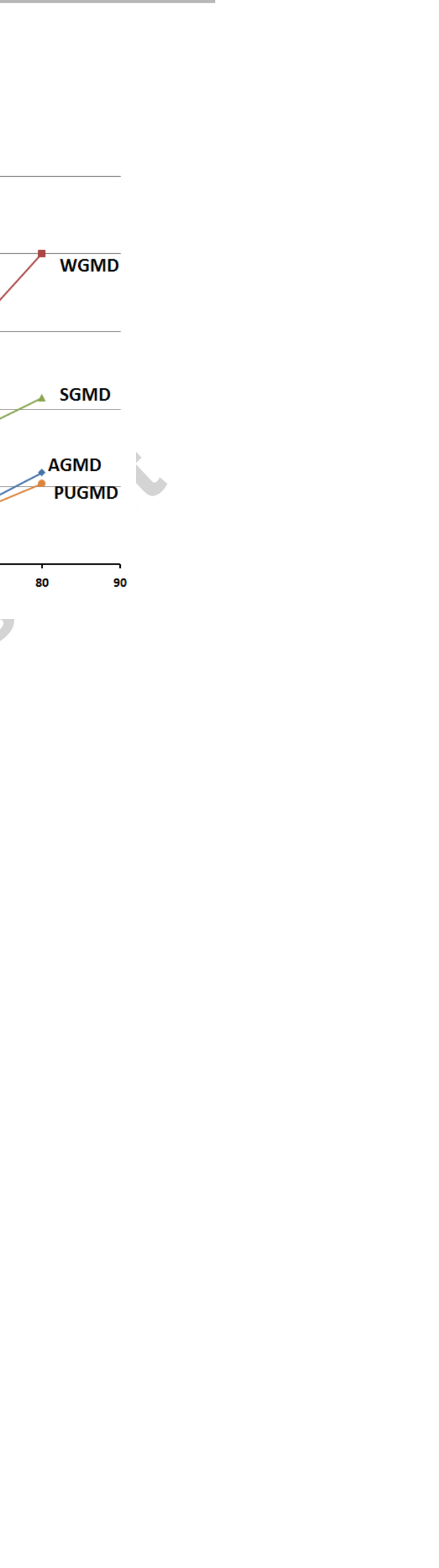

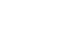

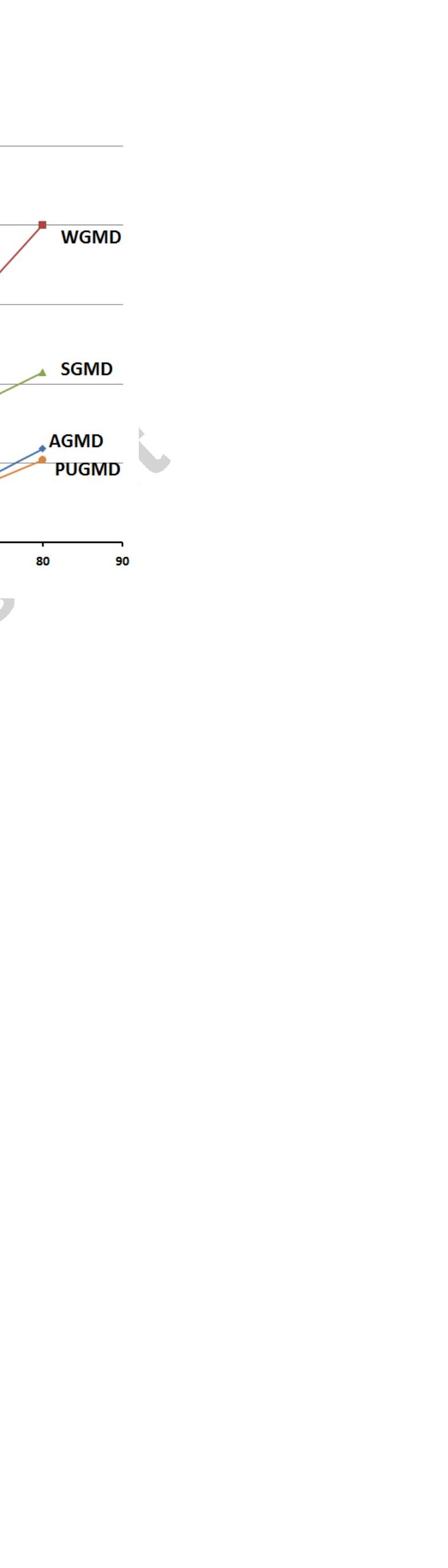

-

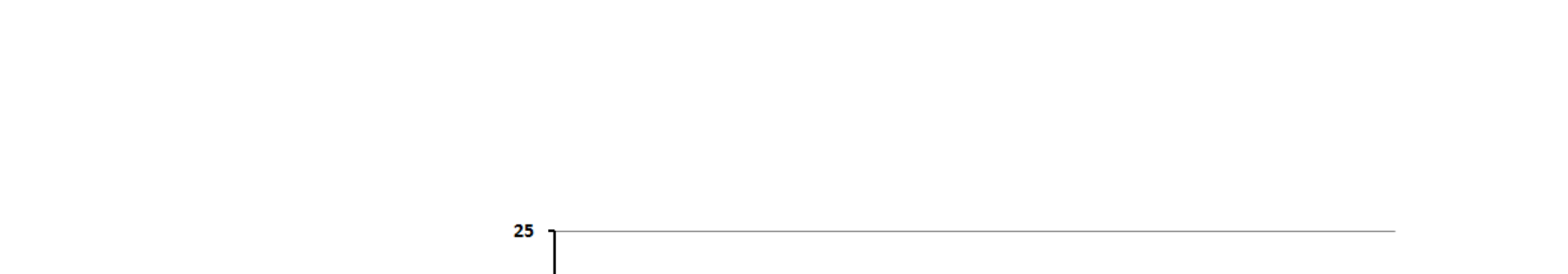

r

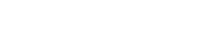




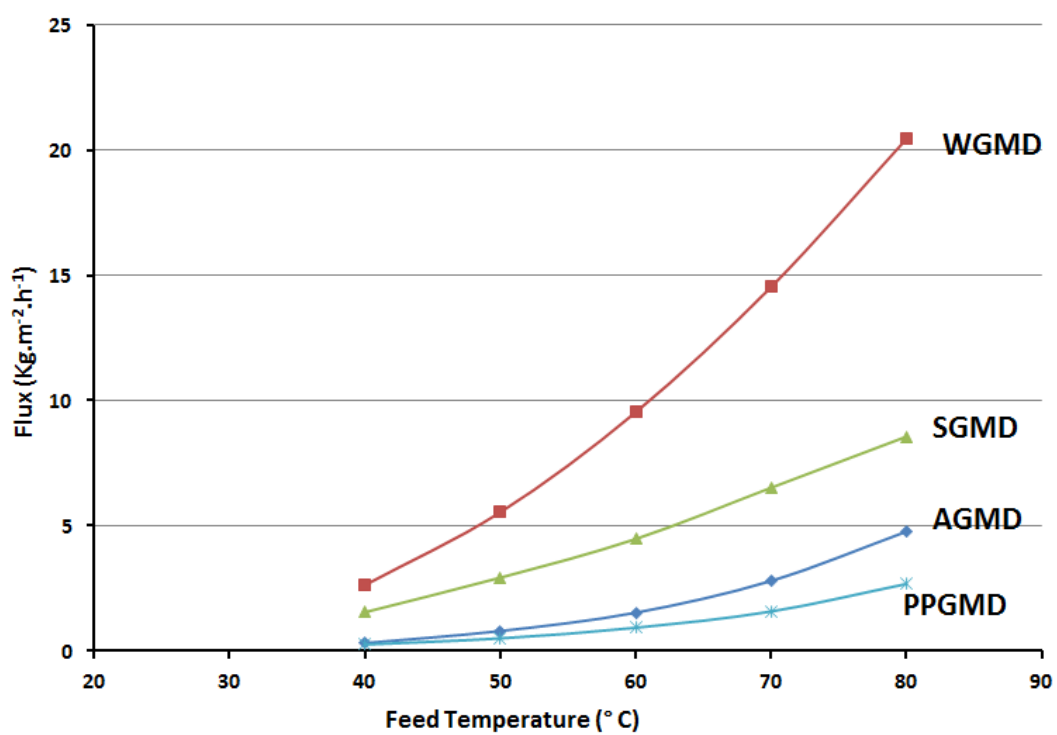

Figure 4 


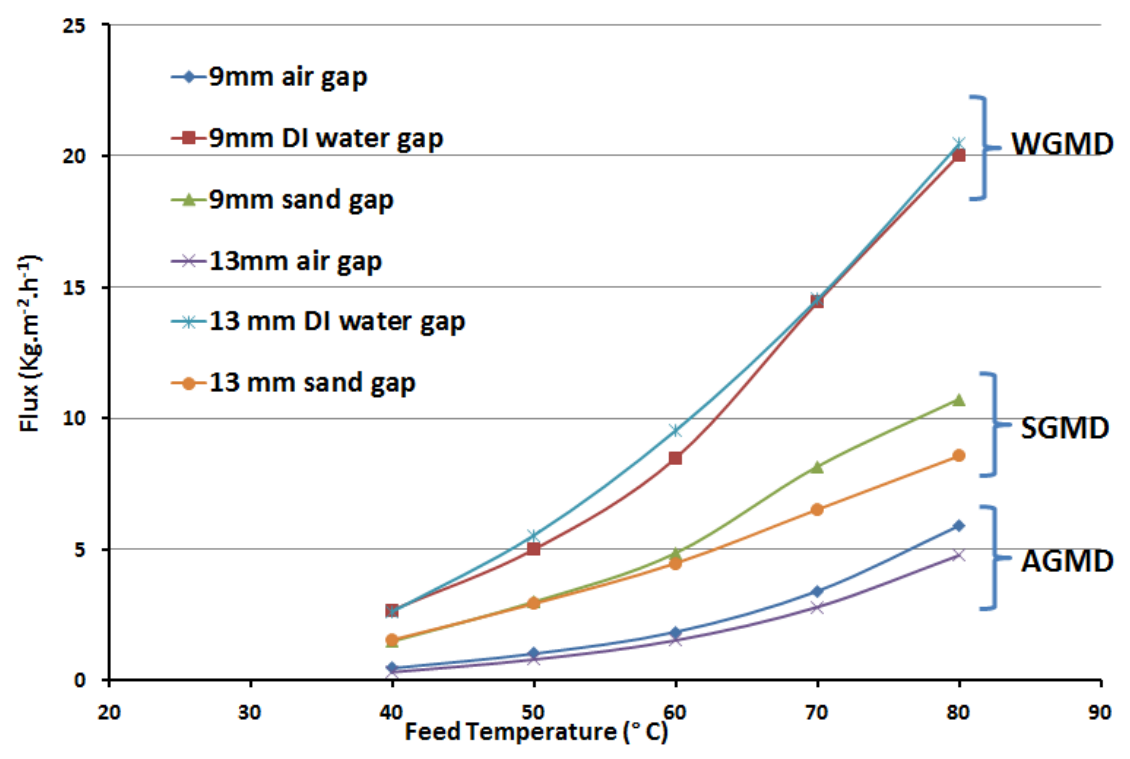

Figure 5 


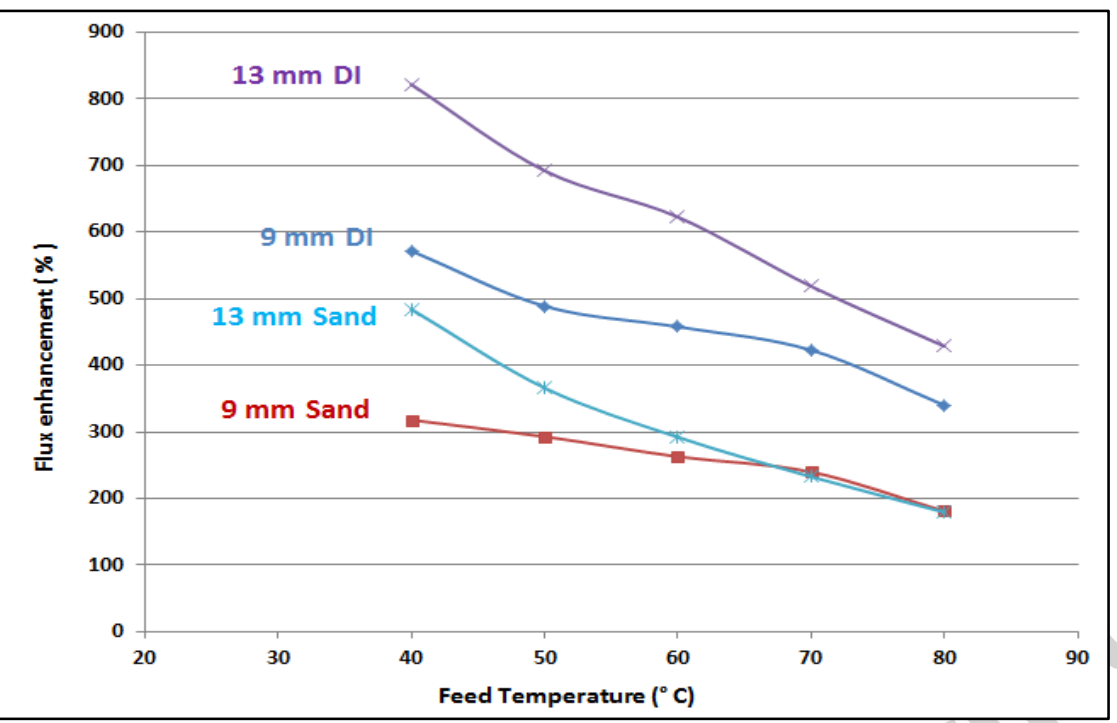

Figure 6 


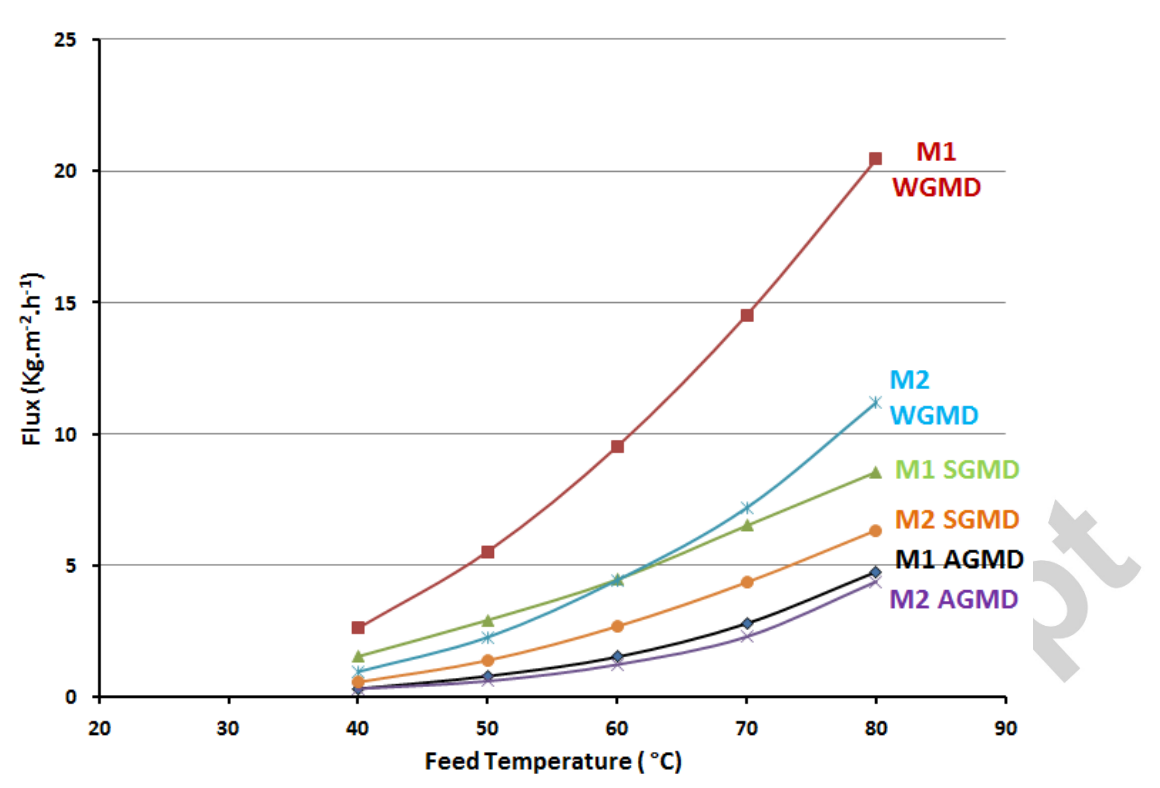

Figure 7 


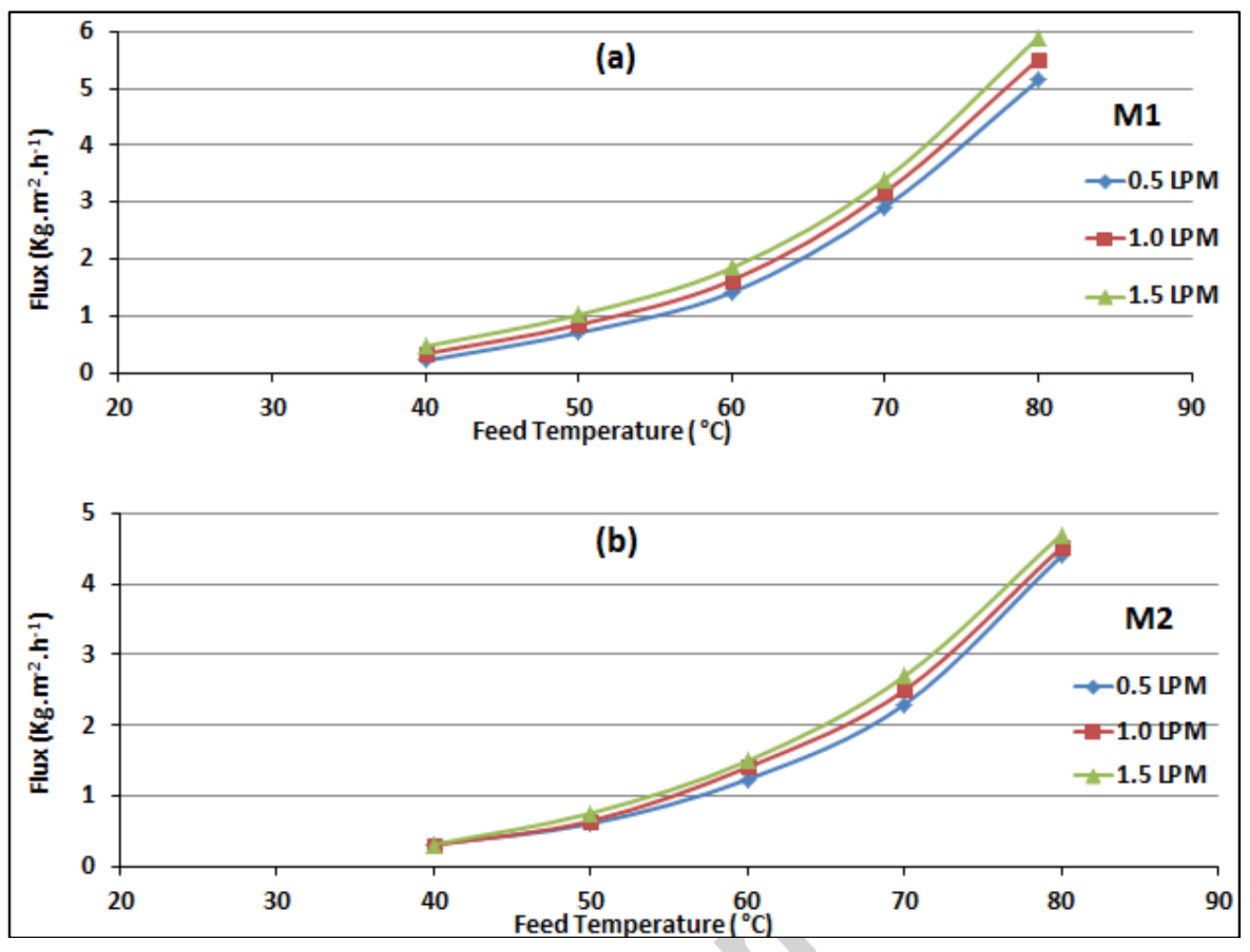

Figure 8 


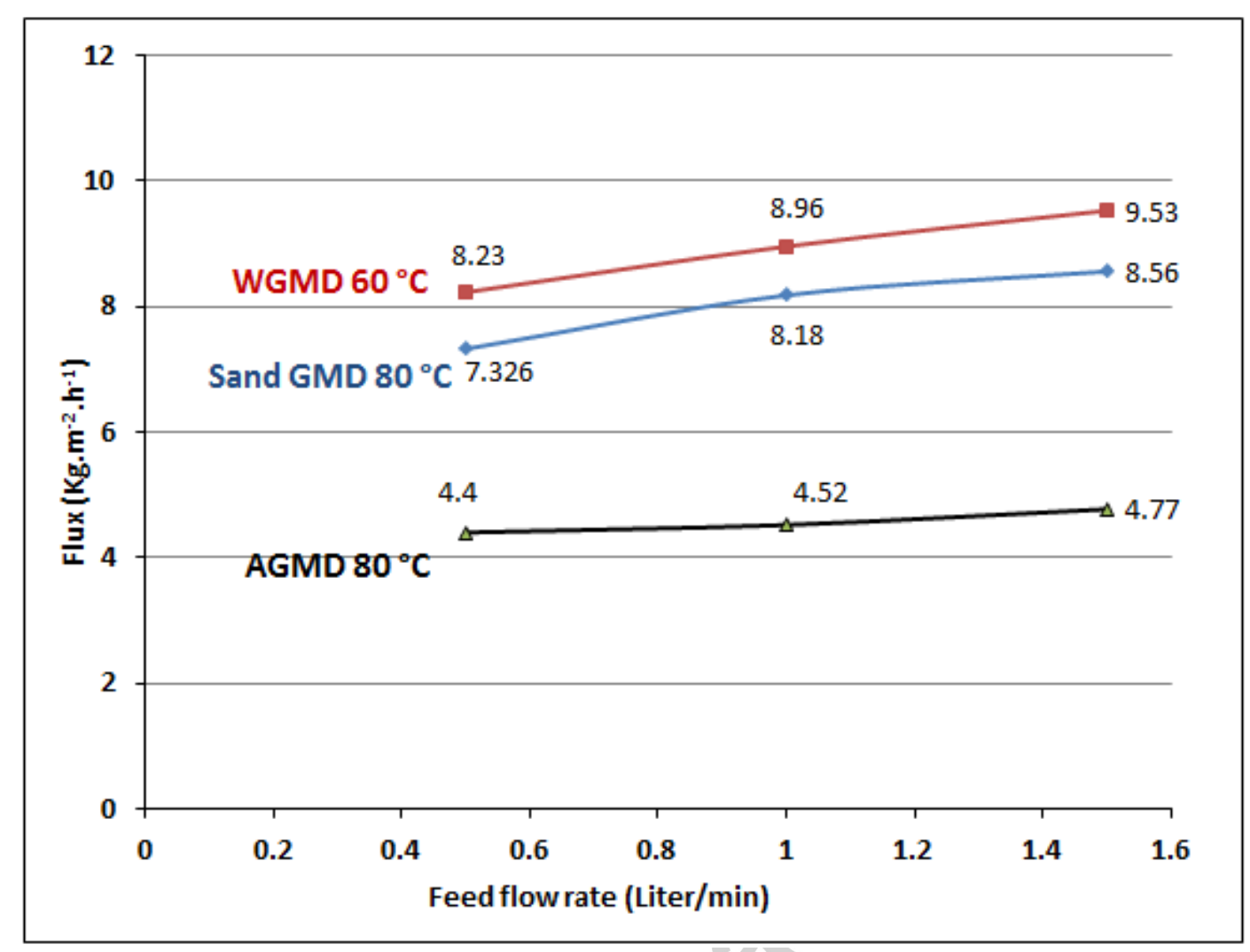

Figure 9

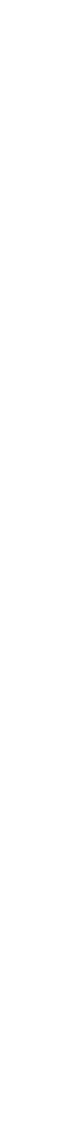




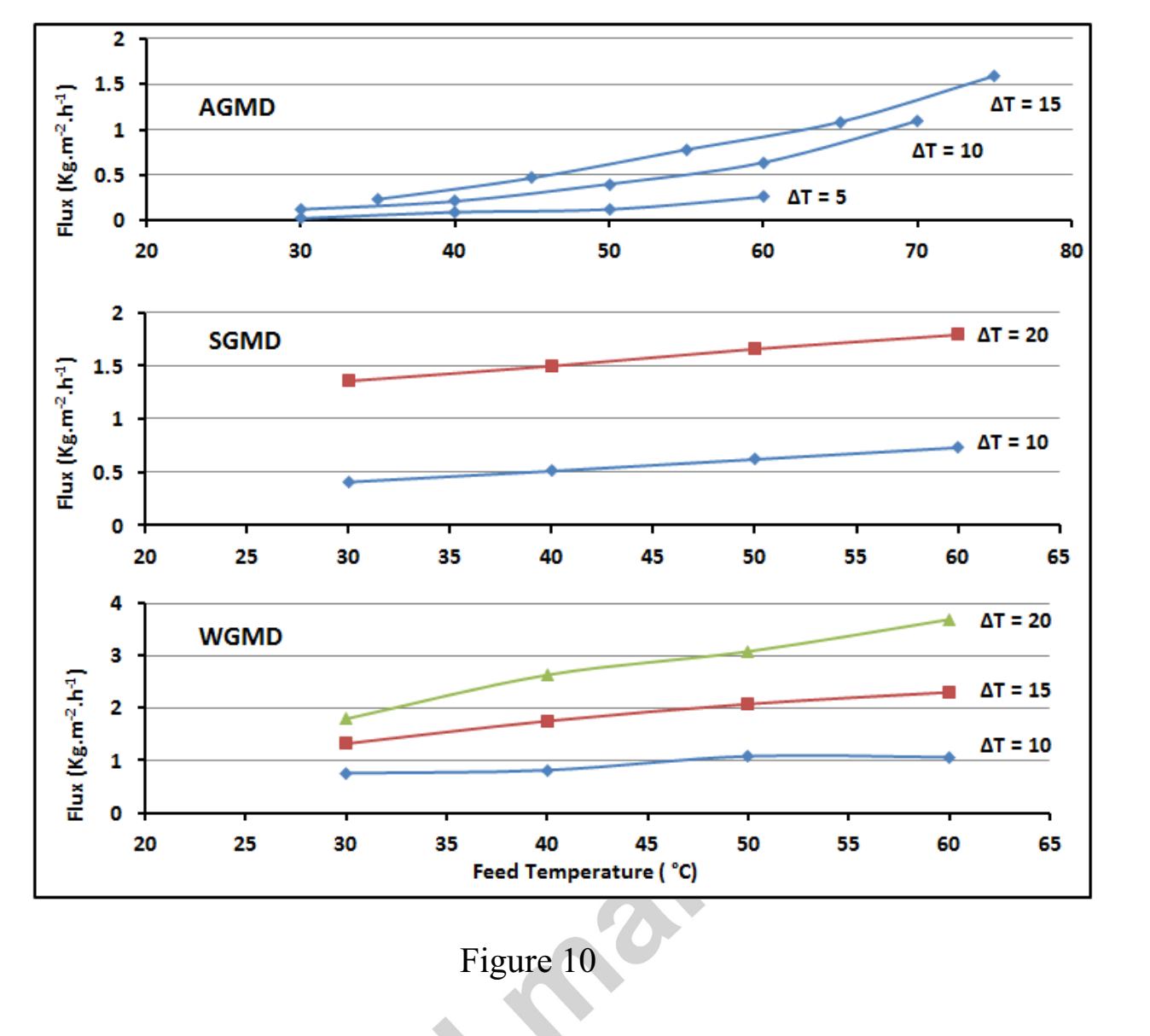

Figure 10

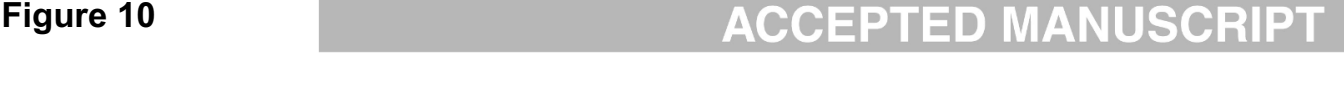

$$
\text { . }
$$
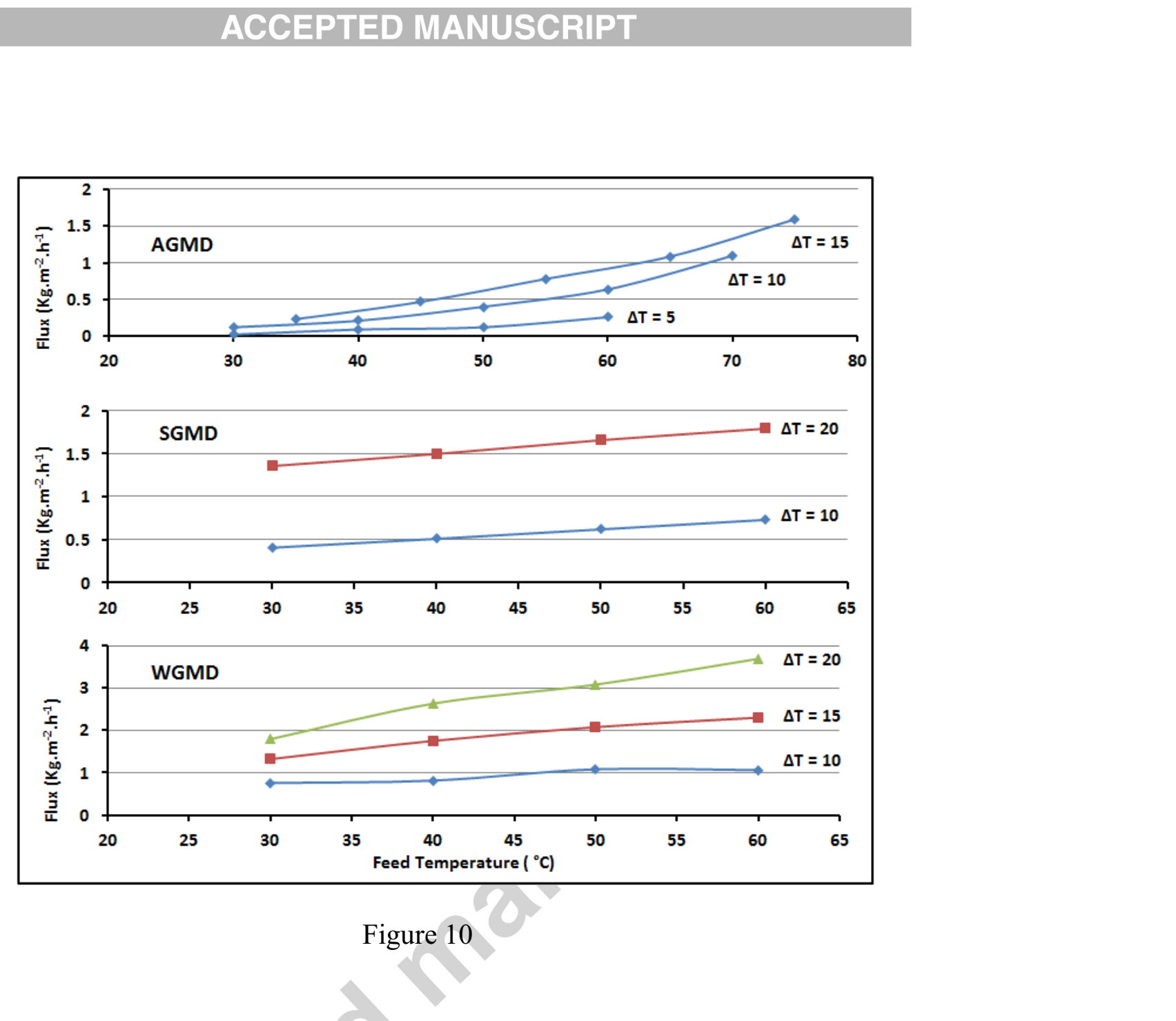


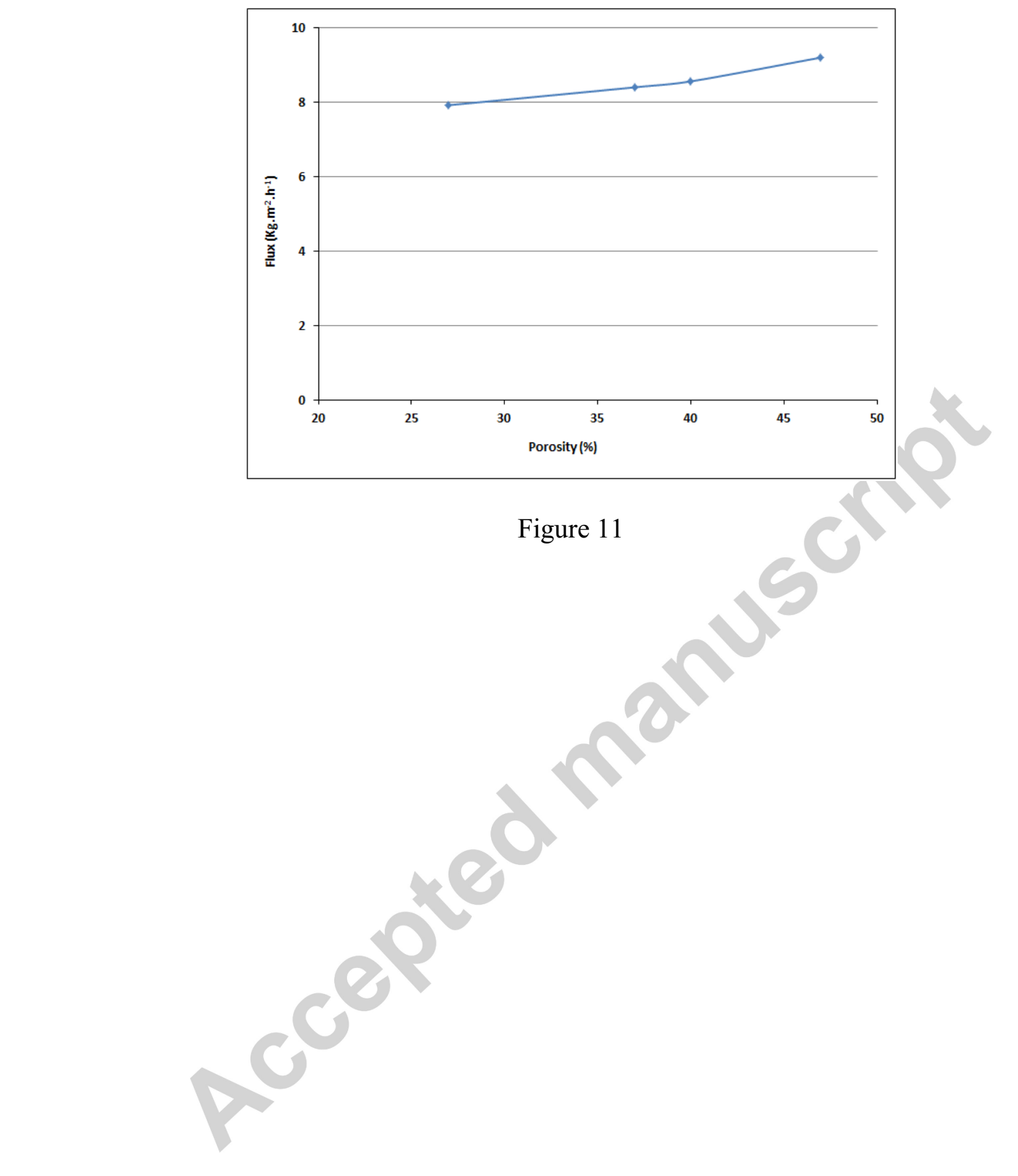

Figure 11 ACCEPTED MANUSCRIPT
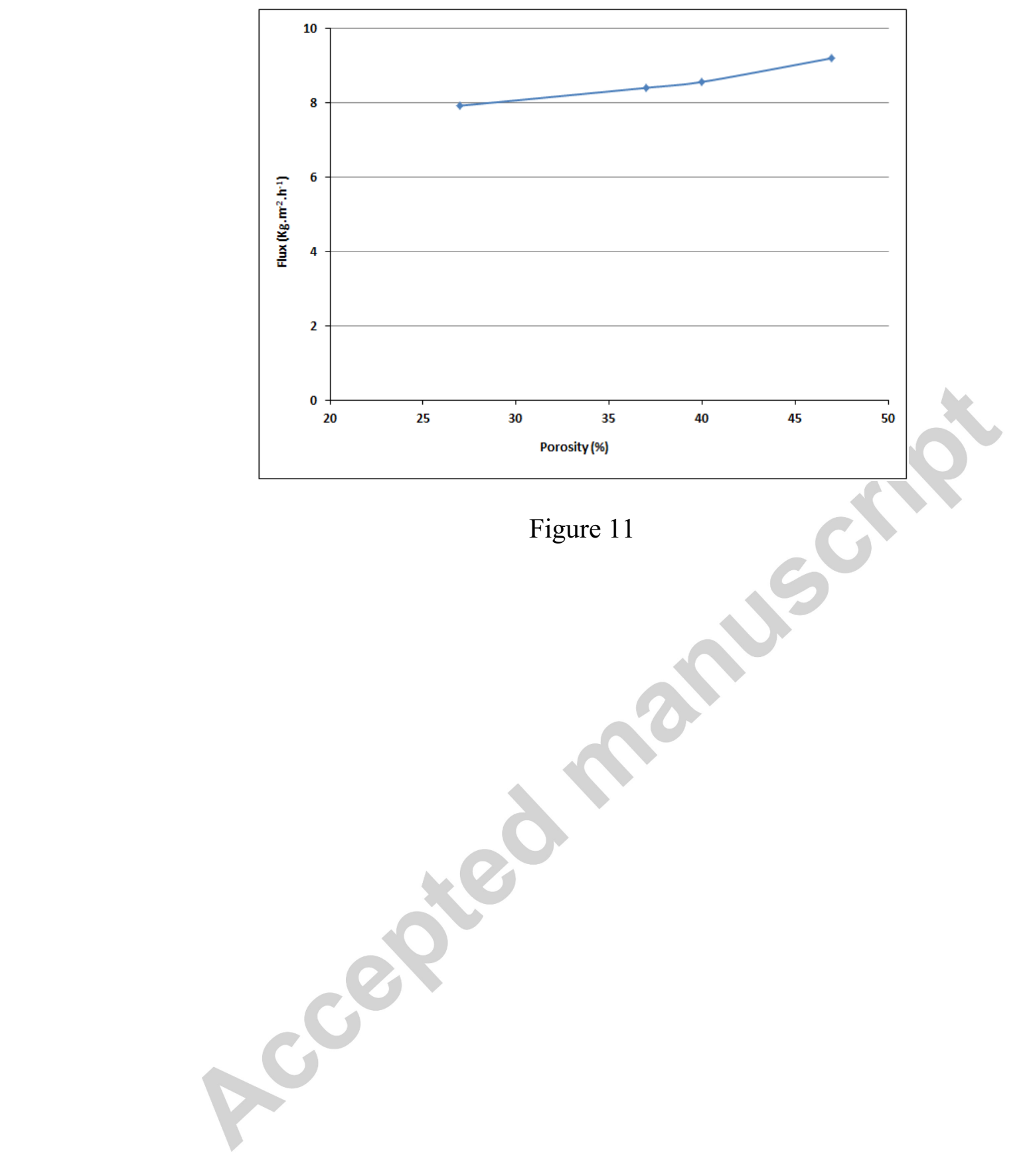

.
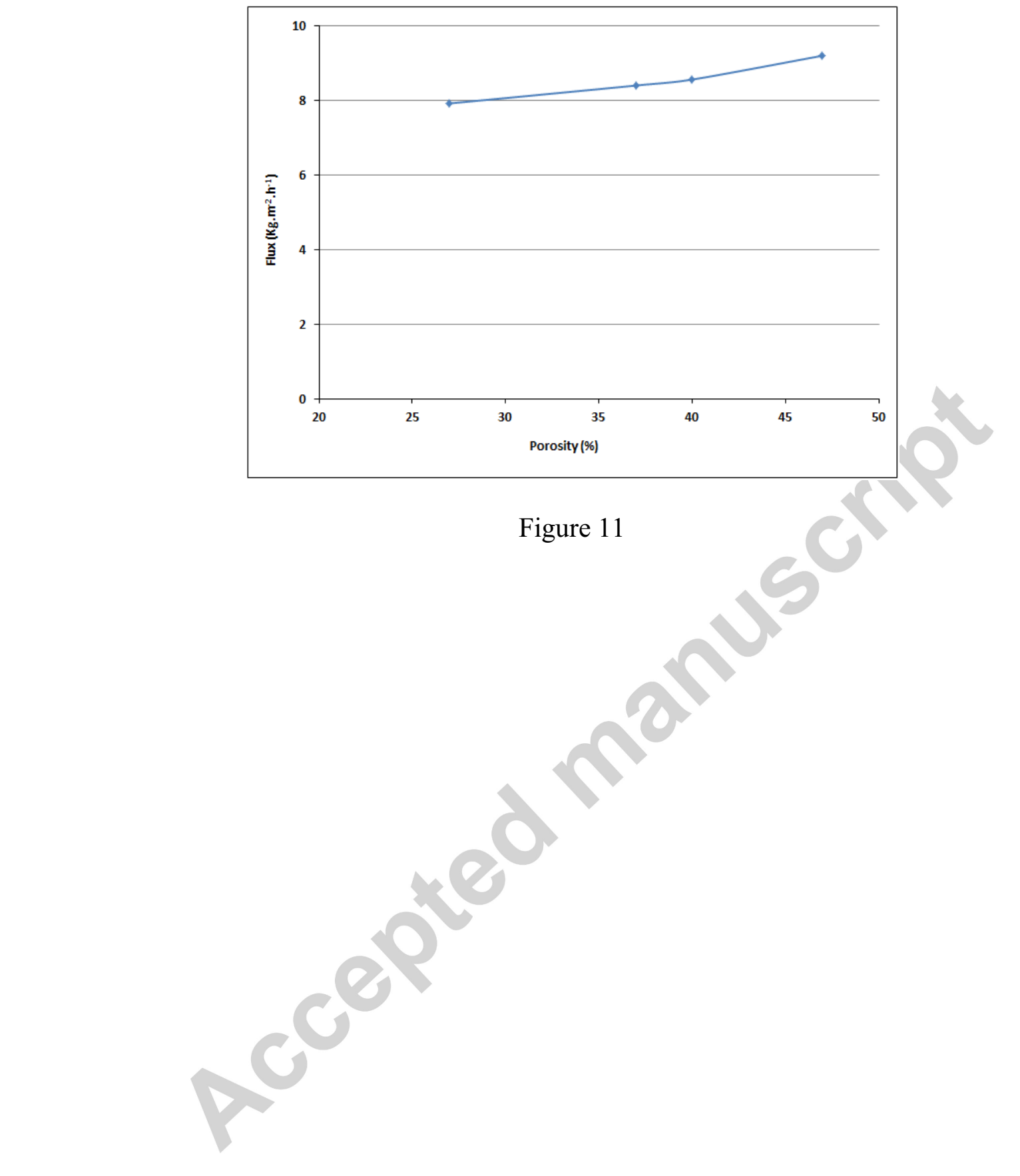